\title{
Technology and Secondary Writing: A Review of the Literature
}

\author{
Matthew U. Blankenship \& Erin E. Margarella \\ University of South Florida, United States
}

\begin{abstract}
This article reports a review of the literature that focused on relationship between writing instruction and technology in the secondary classroom since the passing of the No Child Left Behind Act over the past two decades. Based on the search, six themes have emerged across the fields of writing instruction and assessment. Within writing instruction, it was found that researchers often focused on a third space (Bhabha, 1994) where writing can take place in meaningful ways. Also, technology often served as a motivator during the instructional process of writing and worked to engage students in varied lessons. Finally, researchers found an increase in the amount of writing for secondary students when technology was introduced into the instructional classroom. Within writing assessment, the research focused on special populations including special education students, minorities, economically disadvantaged and English language learners. Next, technology served as a motivator in both the instruction and assessment of writing and tended to be a factor that increased writing assessment scores. Finally, researchers posit technology can be used to allow teachers to give effective and efficient feedback through the instructional and assessment cycles and tended to increase student assessment scores. These themes emerged across all articles reviewed and truly demonstrate where writing with technology research has occurred in the secondary classroom.
\end{abstract}

Keywords: Writing; Instruction; Technology; Policy; Secondary Education; Motivation

\section{Introduction}

Due to the mandates associated with No Child Left Behind (NCLB), there has been an increased focus on assessment and accountability in today's schools. While focusing on these mandates, schools must also take the time to prepare each population of students for a future as digitally literate adults. NCLB states that each student must be technologically literate by the 8th grade and, as a result, schools must work diligently to educate students, meet the mandates of NCLB, and create an environment that fosters development of a new, technologically literate, global society. Williams (2003) states, "if we expect students to understand literacy as the ability to decode a system of symbols to create meaning, then this approach to media literacy education has a great deal of value" ( p. 547).

With the passage of No Child Left Behind, writing could have become the forgotten academic subject making way for a focus on reading and math. However, as a reaction, many state and local agencies began developing criteria for including and assessing writing to ensure students 
continued to receive appropriate and varied writing instruction (McCarthey, 2008). Therefore, we conducted a systematic review of the literature to determine: how technology has influenced writing instruction and writing assessment in the secondary classroom since the implementation of NCLB in 2002.

\section{Theoretical Framework}

To conceptualize and investigate writing instruction and assessment with technology, the researchers examined their theoretical framework and views regarding learning, writing and technology. For learning, situated learning theory was used to explain the cognitive and social processes in the classroom. To conceptualize the process of writing, Graves' (1994) writing tenets were examined. This provided a foundational understanding of how writing is used both formally and informally in the secondary classroom. This also provided support for those articles that only partially focused on writing instruction or assessment. Finally, to understand technology, a review and conceptual analysis of Nicolini's (2007) tenets of technology was conducted to support learning in the classroom.

Situated learning theory is a constructivist view of learning that focuses on meaning, practice, community and identity (Wenger, 1998). Student experiences develop meaning through practice within a community of learners. From this, students develop an identity within their social context and extend learning in formal and informal environments. By following this form, students engage in meaning making through the various interactions of all types of texts they encounter. For writing, students can use writing to engage in discourse in order to learn.

For situated learning, students work in both formal and informal spaces in order to gain a better understanding of the world they interact with on a daily basis (Lave \& Wenger, 1991). This allows students the opportunity to learn through apprenticeships from both formal and informal teachers. As students mitigate these formal and informal experiences both in and out of the classroom, they begin forming an identity that reflects their experiences and understandings. As students progress through the learning process, they move from being a novice to the role of expert (Lave \& Wenger, 1991). This moves them into the teacher role for the next student. In order to truly develop situated learning within the classroom, teachers and educators must take advantage of both formal and informal activities for instructional opportunities. In addition, teachers should develop authentic activities that reinforce concepts in a real world content (Lave \& Wenger, 1998). Writing can easily mimic this type of activity by allowing students to engage in multiple writing mediums.

Graves (2007) developed tenets for writing to learn in order to conceptualize the act and process of writing. These ideas provided focus for this search as we reviewed articles about writing instruction and assessment. As an extension of situated learning (Lave \& Wenger, 1998), Graves (2007) viewed writing in both formal and informal spaces. Students utilize writing in authentic manners in order to continue developing writing style and content understanding (Graves, 2007). In addition, teachers should communicate and allow students to communicate in writing without feedback, to provide a more authentic writing experience. As Graves (2007) states, "writers need to get it down before they worry about getting it right" (p. 67). 
Graves (2007) outlined tenets in order to guide teacher and researcher thinking about writing in the classroom. These tenents include the following ideas:

1. Writing is a social act; talk is part of the process

2. Writing is a process; there are many writing processes

3. We get better at writing by writing

4. To invest in writing, students need choice, response, and time

5. Clear, logical writing reflects clear, logical thinking. Because students think in all content areas, it follows that students should write in all content areas

6. Writing is communication; the ability to communicate is essential

7. Fluency must be developed before clarity; clarity (control) must be developed before accuracy and correctness (precision). Writers need to get it down before they worry about getting it right (p. 67).

By viewing writing through these tenets, the act of writing was conceptualized as a social process focusing on student choice, variety of outlets and the role of feedback. Through this, we posit the act of writing to be a messy, multifaceted process that develops over time. Technology can support this through the classroom environment.

Nicolini (2007) developed tenets to structure how technology can support learning in the classroom environment. These tenets provided a lens to view technology in the secondary writing classroom. Nicolini (2007) demonstrated that technology can serve as an asset to instruction and should be infused whenever appropriate. In addition, teachers bear the burden of responsibility to teach students the appropriate use of technology in authentic manners. This will enable students to navigate the greater world that incorporates technology in all aspects of society. This includes developing an understanding of how sources are presented and what makes the information valid (Nicolini, 2007).

As a guide for this review, Nicolini's (2007) tenents are:

1. Classroom instruction and information management can be strengthened through the efficient use of technology

2. Technology can support student learning

3. The information explosion requires that appropriate changes in curriculum and instructional delivery take place

4. Students need to know how to access and select from the avalanche of information to help them solve problems

5. Technology can and should facilitate the rethinking and the restructuring of what takes place in the classroom (p. 67). 
These tenets call for classroom technology use to be intentional and relevant. In addition, they include the need for teachers and educational leaders to make informed decisions about when and how to include technology instruction in the classroom. This intentional inclusion of technology instruction can support students as they encounter new literacies within society (Nicolini, 2007)). This can lead to a complete change in how the classroom is situated.

Based on these three ideas, technology was viewed as infusing the writing classroom as a social area that provides multiple uses of technology-mediated writing opportunities that offer a variety of experiences and choices for students. Technology mediated writing in a socially constructed space allows students to construct meaning from their writing with peers, teachers, and environments in addition to the technology itself.

\section{Research Methods}

Our systematic approach to conducting this literature review included both searches of databases as well as hand searches of scholarly, peer-reviewed journals. Our initial search included a database search of Education Full Text and ERIC. Our database search terms included: Writing instruction technology + secondary OR high school OR middle school and writing + assessment technology + secondary OR high school OR middle school. Following our database search, we conducted a hand search of "Written Communication" and "The Journal of Adolescent and Adult Literacy" because they represented a large area of writing research in the secondary classroom. To narrow the focus of our search, we included the following delimitations: only articles related to student writing and technology, as opposed to teacher writing or writing professional development. Student writing includes both formal and informal writing activities completed by the student either in or out of the classroom. In addition, only studies conducted in the United States were considered in order to focus on the effect of No Child Left Behind. Only studies related to middle and high school students as well as only those studies published after the implementation of No Child Left Behind (2002). Finally, in order to increase the validity of our search only those articles published in peer-reviewed, scholarly journals were included in the review. In addition, we included several foundational pieces to situate our understanding of writing instruction and assessment and technology in both the introduction and as connecting pieces within the body of our review. Our search yielded 46 articles.

The database search originally returned 100 articles. After reviewing titles and abstracts, 61 articles were excluded leaving 39 relevant articles. These articles focused on issues outside the scope of this review including teacher writing, studies conducted on students outside of the United States, elementary students, or pre-service teachers. In addition, many of the various search combinations returned the same articles within the results. During our hand search, we reviewed the table of contents for each issue from January 2002. By reviewing the titles of articles, we decided to include or exclude. For articles that were included, we first read the abstract to ensure it had a relevant focus to our review. Following this process, seven articles were left relevant to the scope of this research.

To begin our review, we initially read the articles looking for common themes among the articles looking for emergent themes using the constant comparative method described by Glasser and 
Strauss (1967). This included reading and rereading the articles, looking for themes grounded within the body of research itself. This was done separately by each researcher and then compared through discussion. This produced two broad themes of instruction and assessment. In addition, we each noticed the smaller themes prevalent. These include writing achievement, motivation, expertise, special populations, and feedback. We then met again to discuss our findings and reconciled the differences between our understandings of the articles. This produced the review as presented below.

\section{Emergent Themes}

By thoroughly reviewing the research, coding each article thematically, and situating each finding utilizing the constant comparative method from Creswell (2007), six prevalent themes were identified as common factors in the broader categories of writing instruction and writing assessment. This served as our results for the article. Within writing instruction, researchers often focused on a third space (Bhabha, 1994) where writing can take place in meaningful ways. Next, technology often served as a motivator during the instructional process of writing and worked to engage students in varied lessons. Finally, researchers found an increase in the amount of writing for secondary students when technology was introduced into the instructional classroom.

Within writing assessment, the research focused on special populations including special education students, minorities, economically disadvantaged and English language learners. Next, technology served as a motivator in both the instruction and assessment of writing and tended to be a factor that increased writing assessment scores. Finally, researchers have found that technology can be used to allow teachers to give effective and efficient feedback through the instructional and assessment cycles and tended to increase student assessment scores. These themes emerged across all articles reviewed and truly demonstrate where writing with technology research has occurred in the secondary classroom.

\section{Instruction}

Following a review of relevant research on writing, technology, and instruction, three themes emerged. The first theme that emerged was, when used appropriately and effectively, technology can support improvements in overall student writing achievement. The second prominent theme was the medium of technology can be used to motivate and inspire students to compose text. A final theme that emerged from the literature was technology can assist in students developing greater content expertise within their writing. Such expertise can be noted as students move toward a third space (Bhabha, 1994) of understanding.

\section{Technology Can Improve Student Writing and Overall Expertise}

Within recent years, there has been a shift toward utilizing media literacy within education, but even with the presence of such a shift, little attention has been paid to the pieces of written text 
students create as a result of such media (Williams, 2003). The use of "multimedia software provides teachers with several means by which they can creatively integrate curriculum and instruction with technology" (Rao, 2009, p. 27). Students use multimedia software and hardware to exercise control over their learning (Ferreti \& Okolo, 1996), make decisions, and create written text aligned with their level of understanding. Such coursework allows for meaningful interactions among students and teachers where learning can be enriched and supported (Rao, 2009) while still operating within the Zone of Proximal Development (Vygotsky, 1962).

According to Rao, (2009) educational theorists believe, through the integration of multimedia projects, students will "have the potential to improve creativity, problem-solving abilities, and content-area knowledge" (p. 28). In a 2001 multimedia case study, Dimitriadi (2001) found when technology was integrated, students' level of fluency improved on self-created passages. Harris (2002) noted that through the use of primary source examination, student writing improved. Because access to such primary source information has been limited, the use of technology offers unlimited possibilities for student inquiry and achievement (Harris, 2002). Rather than relying on a textbook, students and teachers are now able to utilize technology to support the content area textbook and then move beyond. Artifacts not readily available through traditional texts are easily accessible through digital texts and media. With widely available technological support (blogs, digital book talks, movie making, shared writing, interactive feedback, wiki pages, web pages, and multimedia projects) teachers are able to support improvements to analytic and creative writing (Fasulo, Girardet, \& Pontecorvo, 1998). As posited by Nicolini (2007), the use of "technology in a writing process classroom allows teachers to get out of the way and let students compose" (p. 67).

\section{Technology Can be Used as an Effective Motivator for Students}

Technology can be utilized as an effective means of motivating students to compose and construct a variety of texts. Technology does not simply motivate; it reengages students in the learning process and improves academics (Rao, Dowrick, Yuen, 2009). Bazerman (2004) posits by studying writing across genres, it is possible to see the ways ideas are organized in addition to the ways people position themselves around ideas. The methods and choices made by students regarding their construction of technologically supported texts can reflect a belief that technology is their literacy (Gee, 1989). By teaching and supporting writing through the use of a medium that reflects the interests and desires of students, teachers empower students to make decisions and create personally relevant texts.

Through the use of technology in the writing classrooms, students are able to easily compare their community of practice (Wenger, 1998) with anothers, regardless of location (Bass \& Rosenzweig, 1999). Students may communicate with other student populations while using the Internet or research ideas and concepts to build on their prior knowledge. Fasulo, Girardet, and Pontecorvo (1998) note the importance of group and joint discussion for promoting community and encouraging imaginative thinking. Faux (2005) posits that technology supports an environment in which students gain a sense of independence and motivation to engage in the writing process.

Students can become immersed in a textual environment supported by other students who share common interests and beliefs. Such students may not be present within their school or classroom 
(Tarasiuk, 2010), but can be readily accessible when technology is effectively utilized. Because students, in a technologically wealthy environment have many choices of mediums and textual outlets, students are empowered to make decisions regarding which medium would prove to be most relevant to their writing. While students may initially rely on their teacher for support, with appropriate scaffolding and experience, students are able to utilize the technology to improve upon their writing, make informed decisions, and create more personally relevant pieces of text.

\section{Technology Can Support a Deeper Understanding of Content}

Through the use of technology, students can develop a deeper understanding of content in addition to becoming more advanced writers and discourse participants. It is possible "the greatest potential of multimedia is that it allows teachers to create environments where students can be researchers and creators of products for reports, becoming experts in certain subjects" (Wissick, 1999, p. 502). This expertise is reflective of a deeper, more thorough understanding of a given topic or subject.

As noted by McKeown and Beck (1994), the authors of textbooks often assume students have a certain level of prior knowledge. Frequently, this assumed level is below what the student is actually able to demonstrate. In addition, many textbooks are simply not engaging (Harris, 2002) and do not effectively motivate students to delve deeply into a given piece of content. Wineburg (1991) noted that students viewed primary textbook sources as being the most credible, authentic, and unbiased regardless of the authenticity of the content included. To supplement textbooks, which often lack credibility, teachers can utilize digital media. Such media provides opportunities for increased learning as well as the composition of a variety of meaningful texts. Witte (2002) posits by simply, "combining writing with online technology, teachers can provide opportunities for students to develop their digital fluency while also strengthening their traditional literacy skills" (p. 92). Levstik and Barton (1996) ascertain that most students are concrete thinkers and have a strong situated need to interact with actual artifacts to truly learn. Through the use of these artifacts, whether tangible or digital, students can move toward a deeper, more advanced level of understanding on a given topic.

To accommodate a shift toward a more technologically integrated curriculum, teachers can update their method of information transmission by integrating primary source information into PowerPoint presentations or other digital mediums rather than simply lecturing or passing around a book (Harris, 2002). When careful attention is applied, the level of interpretive and critical skills used to interpret media texts becomes extensively pervasive (Williams, 2003). The use of such digital media not only frees the teachers from a traditional dependence on written text, but will promote an open, guided experience for students in which inquiry and exploration are at the forefront of the learning experience (Harris, 2002).

Through the convergence of literacy instruction with Internet technologies, a fundamental reshaping of the nature of literacy instruction has occurred. Teachers are actively seeking to prepare children for a future in the digital world (Leu \& Kinzer, 2004). Because of this phenomenon, many researchers are expecting the use of blogs and other digital discourse mediums in the classroom to continue to grow at an extraordinary pace (Oravec, 2002). Such 
digital discourse allows students multiple opportunities to move toward a deeper level of comprehension of material. This deeper level of transdisciplinarity is referred to as the third space (Bhabha, 1994). Within the third space, a complex intersection of ideas and knowledge can be identified. Students can move beyond their textbook understanding of a given topic and into a meaningful, relevant level of expertise. Through their ability to bridge an awareness of technology from home to school (Tarasiuk, 2010), accessing the third space becomes more accessible than within a traditional classroom setting. When students are able to cross such borders to collaborate and create text, they pool their expertise and knowledge, generating new knowledge and develop more complex understandings of their topic of study (Moje et al, 2004).

\section{Assessment}

Researchers complete a high percentage of writing research in the special population classroom. These studies often show a mixed set of results. In addition, researchers often focused on how technology can increase motivation and positively affect the writing assessment outcome. Researchers offer various reasons for this phenomenon and this idea deserves further study. Finally, technology can provide an efficient means for providing feedback to students completing writing tasks. Researchers offered multiple uses of technology to make the assessment and feedback process more effective and/or efficient.

\section{Focus in the Special Population Classroom}

Special population classrooms are defined as classrooms catering to special education students, students with emotional, physical, or behavioral disabilities, minority students and English language learners within the research reviewed (Horkay, Bennett, Allen, Kaplan, \& Yan, 2006; Kinzer, 2010; Lee, 2008; Rao, Dowrick, Yuen \& Boisvery, 2009; Warschauer \& Matuchniak, 2010; Wosley \& Grisham, 2007). Technology is infused in the special population classroom through writing assessments and embedded within instruction (Lee, 2008; Rao, Dowrick, Yuen \& Boisvery, 2009). While no rationale for the focus in the special populations classroom was provided by the original researchers within the literature, this finding was prevalent in multiple studies. With this in mind, researchers have focused writing and technology research within the special education classroom (Horkay, Bennett, Allen, Kaplan, \& Yan, 2006; Kinzer, 2010; Lee, 2008; Rao, Dowrick, Yuen \& Boisvery, 2009; Warschauer \& Matuchniak, 2010; Wosley \& Grisham, 2007). Based on the findings of the various articles reviewed, researchers have mixed reactions on how effective technology and writing instruction is on assessment outcomes. According to the studies reviewed (see below), these effects were often related to the implementation or purpose of the infused technology.

Rao, Dowrick, Yuen and Boisvery (2009) focused on how technology affected the writing abilities of high school students who had learning, emotional or behavioral disabilities. Through this study, the teacher immersed students in a "multimedia environment" during the writing process in which students worked and completed assessments in the digital space (pg. 27). The researchers found students were more engaged in the environment and tended to obtain higher assessment scores on writing tasks. Kinzer (2010) found a similar effect with English language learners. In a study of 
adolescent English language learners utilizing online communities, Kinzer (2010) determined that online fan-fiction communities could increase engagement and motivation in English language learners during writing activities and this correlated to increased writing assessment outcomes in the separated classroom. The researchers related this to an increase in personal connections to the material instead of a traditional writing on a random topic.

Even with these outcomes, some researchers are calling for additional research in the special populations to confirm the correlation with assessment outcomes. According to Rao, Dowrick, Yuen and Boisvery (2009), "teachers seem to be more aware of the motivational benefits of using technology in special education than the academic benefits, but researchers are trying to broaden this understanding by confirming the value of technology and student achievement" (p. 27). These researchers believed the special population student experiences a rise in achievement levels based on a motivation factor. The researchers found technology allows special population students feel a sense of "expertise" when completing academic tasks in a multimedia environment and it "improves academic skills" (Rao, Dowrick, Yuen, \& Boisvery, 2009, p. 28). In addition, students tended to complete more of the assignment when technology was incorporated.

All students showed improvements on their written products. One student changed his writing behavior and authored the longest free-writing piece he had ever produced. Another student, with low motivation, produced 10 stories. The student with the most severe disabilities displayed improvements in her writing processes and an aptitude for spelling that teachers had not previously seen (Rao, Dowrick, Yuen, \& Boisvery, 2009, p. 28).

A unique outcome of this study showed students who were closer to grade level showed very little effect from technology integration while students who had a larger gap showed vast improvement. Rao et al (2009) believed this was due to a ceiling effect. A similar result emerged from Wolsey and Grisham's (2007) research with male students. Wolsey and Grisham (2007) also found by that including technology within the instructional portion of a lesson, male students who received special education services improved writing assessment scores. The researchers believed this correlated to their interest in computer simulation games outside of the school environment and correlated to increased participation in the writing process (Wolsey \& Grisham, 2007).

As a different outcome, Warschauer and Matuchniak (2010) reviewed several studies focused on technology in the special populations writing classroom. The prevalent theme the researchers found indicated special population students experienced a neutral or negative effect on literacy achievement, including writing, because of an "unproductive use of technology" and this may limit the benefit students receive (pg. 203). Horkay, Bennett, Allen, Kaplan, and Yan (2006) found special population students did not fare better when technology was infused during the assessment activity. These researchers also linked stagnant and downward achievement to the unnecessary use of technology in the writing program and believed technology for token purposes proved detrimental.

The research on writing assessment with the infusion of technology in the special population classroom is mixed. Some researchers found a positive effect on assessment outcomes for writing after the use of technology while others found little to no effect. This demonstrates a need for 
increased research in the special population classroom to determine a more consistent assessment outcome.

\section{Technology as Motivation}

Researchers often noted that technology served as a motivator for students to complete and improve writing in both the instructional and assessment processes (Dikli, 2006; Gibbons, 2010; Kinzer, 2010; Tharp, 2010; Wolsey \& Grisham, 2007). Many researchers, however, noted a concern. This included using technology for meaningful instructional purposes and warned irrelevant or ineffective uses such as maintaining computerized files or writing on the computer as a word processor only will demotivate students (Dikli, 2006; Gibbons, 2010; Kinzer, 2010; Tharp, 2010; Wolsey \& Grisham, 2007).

Rao et al (2007), in their study of emotionally, physically or learning disabled students asserted, "teachers will realize that technology does not simply motivate; it reengages students in the learning process and improves academics" (p. 28). These researchers believed students were intrinsically motivated because of the independent nature often involved in assignments involving technology, including independent research and writing, group work, or individual and small group presentations. Dikli (2006) found technology provided motivation to students through quick and efficient feedback. According to the researcher, writing assessment programs "offer students a writing environment that provides immediate scoring and diagnostic feedback; that allows them to revise their essays accordingly; and that motivates them to continue writing on the topic to improve their writing proficiency" (p. 18). Tharp (2010) noted students would be motivated by providing contemporary topics "along with the novelty of using the wiki with a group of peers would be the hook that would motivate and engage students" and enhance their writing output for assessment (p. 41). Kinzer (2010) found that "online activities are highly motivating" and can engage students during instructional practices and result in higher assessment outcomes for individuals (p. 54). Kinzer (2010) continues by stating, "literacy-related assignments (such as reports) that have similar requirements and involve similar skills appear to be intrinsically motivating in digital forms, as opposed to purely print-based forms" (p. 54). These studies involved an introduction of technology within the assessing environment and showed that technology itself does not provide motivation. However, effective uses of technology within the instructional and assessment phase of teaching does boost motivation.

Kinzer (2010) warns, however, that technology integration must have an instructional purpose and "because something is popular outside of school does not mean its popularity and motivational value will continue when it becomes a required, school-based activity" (p. 58). Wolsey and Grisham (2007) found a different view of technology in the classroom. Through their research, they found that "technology may not be as motivating a factor in student achievement as it was when it was new in the classroom and fewer students had access to it at home" (p. 33). They continue, however, by stating a motivation factor may still be present if the technology infusion provides a meaningful instructional need and "had a stronger influence on student attitudes toward writing" and correlated to higher assessment outcomes (p. 33). 
Warschauer and Matuchniak (2010) found "internet-connected computers to be a potent tool for [...] motivating and contextualizing literacy practices" and lead to greater achievement in all literacy practices, including writing assessments (pg. 215). In addition, the researchers found the computer alone did not provide motivation. Warschauer and Matuchniak (2010) believe the computer or other technology driven item simply provided access to a "specialized activity, interest, or niche identity" that motivated students (p. 192).

Motivation is important in any educational activity within the classroom and, like all other topics, writing assessment benefits from this. By incorporating technology within the instructional and assessment processes, researchers found that student motivation increased. However, a majority of the research reviewed offered a cautionary note. Technology must serve an instructional purpose in order to effectively motivate students. Technology for token effect tends to have the opposite outcome and can de-motivate students and lower assessment outcomes.

\section{Technology for Feedback}

Technology can provide efficient means to provide feedback to students (Grimes \& Warschauer, 2010; Horkay, Bennett, Allen, Kaplan \& Yan, 2006; Krucli, 2004; Landauer, Lochbaum \& Dooley, 2008). Researchers found automated scoring machines provided a computerized way to provide student feedback but viewed it as progress monitoring or informal assessment or as a second assessment versus replacing the instructor in the process. In addition, researchers found various other ways to increase the efficiency of feedback to students.

As summarized by Dikli (2006) from a comparative review of computer programs judging the functionality and effectiveness of multiple computerized scoring programs, developers see automated tools as a "more practical and effective" way to score numerous student writing assessments (pg. 5). Dikli (2006) asserts computerized evaluation systems provide efficient means to provide feedback to students. Dikli (2006) points out, however, computer systems alone cannot serve as the only measure of feedback. It should be used as a portion of the writing evaluation process serving as a "second or third rater" in order to have "a checkpoint to compare the scores assigned by human readers" (pg. 28). By combining the human and computer score, students tended to receive a more consistent score than when assessed by either the computer program or human scorer. Horkay, Bennett, Allen, Kaplan, and Yan (2006) found assessments utilizing computer based composing and scoring lead to higher scores and longer outputs than traditional paper and pencil tests and human scorers who assessed each essay at a slower pace. The researchers believed students were able to write and revise more on the computer than on traditional assessments. Based on their findings from a subsequent study, the researchers determined older students with faster keyboarding skills tended to perform better than those with slower skills. Secondary students, however, experienced higher scores regardless of keyboarding efficiency. Landauer, Lochbaum \& Dooley (2008) also stated the primary purpose for automatic feedback software as instructional feedback or as a "second opinion on essay exams administered online, including high stakes exams" (p. 48). The automatic feedback software tended to vary in assessment styles varying from holistic qualities to specific writing traits and companies relied on human readers to verify score outcomes (Landauer, Lochbaum, \& Dooley, 2008). 
Krucli (2004) attempted to use technology during the grading process to allow students to remain, "active learners during the assessment process" (p. 47). Through an interactive writing CD, students linked to multiple sources to receive feedback and additional practice to improve assessment scores (Krucli, 2004). One feature on these CDs included access to automated scoring programs that can be used to revise and resubmit essays for increased assessment feedback. Krucli's (2004) preliminary findings support this type of electronic and multifaceted feedback and states it "can become a powerful tool that will improve the effectiveness of writing assessment in the classroom and provide superior returns on the time invested in grading" (p. 52).

Through automated scoring programs, teachers can offer informal feedback to students and provide a second or third rating of formally assessed writing. By combining automated scoring programs and teacher writing evaluation, a more reliable measure of writing ability and provides additional feedback to students. In addition, instructors can utilize various techniques incorporating technology to increase the amount and quality of feedback along with its timeliness. This tends to increase student achievement as they work to increase their individual scores.

Assessment of writing occurs in many stages. From the research available, technology tends to have an effect on the achievement level of students but researchers are still debating the direction and significance of the trends. However, the research that has been completed tends to focus on students in the special population classroom. Teachers in these classrooms incorporate technology during assessment with both feedback and delivery. This included human scorers, computer programs or a combination of both. However, more research needs to be done within other classroom contexts to continue refining the outcomes.

\section{Implications of the Results}

Through this examination of the literature, we raised several implications for writing instruction and assessment with technology in the classroom. These fall into three basic categories: educators, policy makers, and researchers. Each of these groups plays a significant part in the educational decisions made on a daily basis for students.

Educators need to begin focusing on technology that can be used to support a variety of writing activities. These, however, must be well supported by the teacher in order to serve a valid educational purpose. As such, educators need to become advocates for appropriate technology use in the classroom to benefit students and continue to explore new technologies in the classroom that could potentially benefit student learning.

Researchers need to continue examining the use of technology in the classroom to ensure it is a valid instructional technique that supports writing instruction and student growth. The research currently available in the secondary classroom is inconclusive at best and deserves further study in a systematic manner. In addition, researchers need to continue replicating studies in a variety of contexts to validate given practices and develop recommendations for appropriate use. By working together, educators, policy makers, and researchers can increase student learning in the classroom and continue to make writing and technology a priority in schools. 


\section{Conclusion}

There is currently a shift present within society. Lankshear and Knobel (2006) assert there are two mindsets affecting our current system of education. The first includes the traditional paper and pencil approach to learning where production and completion of written text is valued. The second supports a more contemporary understanding of literacy in which participation and connections are valued. Lankshear and Knobel (2006) ascertain the second is what is most important to our students and should be promoted within our modern schools. Unfortunately, these two mindsets are at odds with each other and have resulted in an educational environment that is both confusing and difficult for our students to navigate. As they are bombarded with two different mindsets, they must learn to adapt to both. This includes the educational environment and world at large. In order to help support our students and their learning, educators must find an effective way to blend the modern with the traditional while preparing our students for their adult lives in the digital era.

\section{Acknowledgements}

The authors would like to acknowledge Dr. Jenifer J. Schneider for her support and advise as we completed this article and our doctoral education.

\section{References}

Bass, R. \& Rosenzwig, R. (1999) Rewiring the history and social studies classroom: Needs, frameworks, dangers, and proposals. Journal of Education, 181(3), 41-63.

Bazerman, C. (2004). Speech acts, genres, and activity systems: How texts organize activity and people. In C. Bazerman \& P. Prior (Eds.), What writing does and how it does it: An introduction to analyzing texts and textual practices (pp. 309-339). Mahwah, NJ: Lawrence Erlbaum.

Bhabha, H.K., (1994). The location of culture. London: Routledge.

Creswell, J. W. \& Creswell, J. W. (2007). Qualitative inquiry \& research design: Choosing among five approaches. Thousand Oaks, CA: Sage.

Dikli, S. (2006). An overview of automated scoring of essays. Journal of Technology, Learning, and Assessment, 5(1), 1-36.

Dimitriadi, Y. (2001). Evaluating the use of multimedia authoring with dyslexic learners: A case study. British Journal of Educational Technology, 32, 265-276.

Fasulo, A., Girardet, H., \& Pontecorvo, C. (1998) Seeing the past: Learning history through group discussion of iconographic sources. In J.F. Voss and M. Carretero (Eds.), International review of history education - Vol 2: Learning and reasoning in history. London: Wobum.

Faux, F. (2005) Multimodality: How students with special education needs create multimedia stories. Communication and Information, 5, 167-181. 
Gee, J. (1989) What is literacy? Journal of Education, 171(1), 18-25.

Gibbons, S. (2010). Collaborating like never before: Reading and writing through a wiki. English Journal, 99(5), 35-39.

Glaser, B. G. \& Strauss, A. L. (1967). The discovery of grounded theory; strategies for qualitative research. Chicago, IL: Aldine.

Grimes, D. \& Warschauer, M. (2008). Learning with laptops: A multi-method case study. Journal of Educational Computing Research, 38(3), 305-332.

Grimes, D. \& Warschauer, M. (2010). Utility in a fallible tool: A multi-site case study of automate. Journal of Technology, Learning, and Assessment, 8(6), 1-42.

Harris, F. (2002). There was a great collision in the stock market: Middle school students, online primary sources, and historical sense making. School Library Media Research, 5. Retrieved on 18 April 2014 from http://www.ala.org/aasl/aaslpubsandjournals/slmrb/sImrcontents/ volume52002/harris

Horkay, N., Bennett, R. E., Allen, N., Kaplan, B., \& Yan, F. (2006). Does it matter if I take my writing test on compus? An empirical study of mode effects in NAEP. Journal of Technology, Learning, and Assessment, 5(2). Retrieved on 18 April 2014 from http://ejournals.bc.edu/ ojs/ index. php/jtla/article/view/1641/1488

Kinzer, C. K. (2010). Considering literacy and policy in the context of digital environments. Language Arts, 88(1), 51-61.

Krucli, T. E. (2004). Making assessment matter: Using the computer to create interactive feedback. English Journal, 94(1), 47-52.

Landauer, T., Lochbaum, K., \& Dooley, S. (2008). A new formative assessment technology for reading and writing. Theory into Practice, 48(1), 44-52. doi: 10.1080/00405840802577593

Lankshear, C. \& Knobel, M. (2006). New literacies: Everyday practices and classroom learning. Maidenhead, England: Open University Press.

Lave, J. \& Wenger, E. (1991). Situated learning: Legitimate peripheral participation. Cambridge: Cambridge University Press.

Lee, S. (2008). Beyond reading and proficiency assessment: The rational cloze procedure as stimulus for integrated reading, writing, and vocabulary instruction and teacher-student interaction in ESL. System, 36(4), 642-660. doi: 10.1016/j.system.2008.04.002

Leu, D. J. \& Kinzer, C. K. (2000) The convergence of literacy instruction with networked technologies for information and communication. Reading Research Quarterly, 35, 108-127.

Levstik, L. S. \& Barton, K. C. (1996) They still use some of their past: Historical salience elementary children's chronological thinking. Journal of Curriculum Studies, 28(5) 531-76.

McCarthey, S. J. (2008). The impact of no child left behind on teachers' writing instruction. Written Communication, 25(4), 462-505. doi: 10.1177/0741088308322554

McKeown, M. G. \& Beck, I. L. (1994). Making sense of accounts of history: Why young students don't and how they might. In G. Leinhardt, I. L. Beck, and C. Stainton (Eds.), Teaching and learning in history. Hillsdale, NJ: Erlbaum. 
Moje, E. B., Ciechanowski, K. M., Kramer, K., Ellis, L., Carrillo, R., \& Collazo, T. (2004). Working Toward Third Space in Content Area Literacy: An Examination of Everyday Funds of Knowledge and Discourse. Reading Research Quarterly, 39(1), 38-70. doi: 10.1598/RRQ.39.1.4

No Child Left Behind Act of 2001 (2002). Pub L No 107 - 110, Statute 115, Stat. 1425.

Nicolini, M. B. (2006). Making Thinking Visible: Writing in the Center. Clearing House, 80(2), 66-69.

Oravec, J. A. (2002) Bookmarking the world: Weblog applications in education. Journal of Adolescent and Adult Literacy, 45, 616-621.

Rao, K., Dowrick, P. W., Yuen, J. W., \& Boisvery, P. C. (2009). Writing in a multimedia environment: Pilot outcomes for high school student in special education. Journal of Special Education Technology, 24(1), 27-38.

Tarasiuk, T. J. (2010). Combining traditional and contemporary texts: Moving my English class to the computer lab. Journal of Adolescent \& Adult Literacy, 53(7), 543-552.

Tharp, T. L. (2010). Wiki, wiki, wiki, - what? Assessing online collaborative writing. English Journal, 99(5), 40-46.

Vygotsky, L. S. (1962) Thought and language. Cambridge, MA: Massachusetts Institute of Technology Press.

Warschauer, M. \& Matuchniak, T. (2010). New technology and digital worlds: Analyzing evidence of equity in access, use, and outcomes. Review of Research in Education, 34(1), 179-225. doi: 10.3102/0091732X09349791

Wenger, E. (1998). Communities of practice: Learning, meaning, and identity. Cambridge, MA: Cambridge University Press.

Wineburg, S. S. (1991). Historical problem solving: A study of the cognitive processes used in the evaluation of documentary and pictorial evidence. Journal of Educational Psychology, 83(1), 73-87.

Wolsey, T. D. \& Grisham, D. L. (2007). Adolescents and the new literacies: Writing engagement. Action in Teacher Education, 29(2), 29-38.

Wolsey, T. D. \& Witte, S. (2007). That's online writing, not boring school writing: Writing with blogs and the Talkback Project. Journal of Adolescent \& Adult Literacy, 51(2), 92-96.

Williams, B. T. (2003). What they see is what we get: Television and middle school writers. Journal of Adolescent and Adult Literacy 46(7), 546-554.

Wissick, C. A. (1996) Multimedia: Enhancing Instruction for students with learning disabilities. Journal of Learning Disabilities, 29, 494-504.

Correspondence: Matthew Ulyesses Blankenship, Doctoral Candidate, Department of Curriculum and Instruction, University of South Florida, Tampa, United States 